\title{
An ethyl acetate fraction derived from Houttuynia cordata extract inhibits the production of inflammatory markers by suppressing NF-KB and MAPK activation in lipopolysaccharide-stimulated RAW 264.7 macrophages
}

\author{
Jin Mi Chun, Kyoung Jin Nho, Hyo Seon Kim, A Yeong Lee, Byeong Cheol Moon and Ho Kyoung Kim
}

\begin{abstract}
Background: Houttuynia cordata Thunb. (Saururaceae) has been used in traditional medicine for treatment of inflammatory diseases. This study evaluated the anti-inflammatory effects of an ethyl acetate fraction derived from a Houttuynia cordata extract (HCE-EA) on the production of inflammatory mediators and the activation of nuclear factor-KB (NF-kB) and mitogen-activated protein kinases (MAPKs) in lipopolysaccharide (LPS)-stimulated RAW 264.7 macrophages.

Methods: To measure the effects of HCE-EA on pro-inflammatory cytokine and inflammatory mediator's expression in RAW 264.7 cells, we used the following methods: cell viability assay, Griess reagent assay, enzyme-linked immunosorbent assay, real-time polymerase chain reaction and western blotting analysis.

Results: HCE-EA downregulated nitric oxide (NO), prostaglandin $E_{2}\left(P_{G} E_{2}\right)$, tumor necrosis factor-a (TNF-a), and interleukin (IL-6) production in the cells, as well as inducible nitric oxide synthase (iNOS) and cyclooxygenase-2 (COX-2) expression. Furthermore, HCE-EA suppressed nuclear translocation of the NF-KB p65 subunit, which correlated with an inhibitory effect on $1 \mathrm{kBa}$ (nuclear factor of kappa light polypeptide gene enhancer in B-cells inhibitor, alpha) phosphorylation. HCE-EA also attenuated the activation of MAPKs (p38 and JNK).
\end{abstract}

Conclusions: Our results suggest that the anti-inflammatory properties of HCE-EA may stem from the inhibition of pro-inflammatory mediators via suppression of NF-KB and MAPK signaling pathways.

Keywords: Houttuynia cordata, Inducible nitric oxide synthase, Cyclooxygenase-2, Nuclear factor-kB, Mitogen-activated protein kinase

\section{Background}

Inflammation has been implicated as a pathophysiological mechanism underlying many chronic diseases. Inflammatory responses and clinical symptoms are controlled through cytokines, nitric oxide (NO), and lipid mediators, including prostaglandins and leukotrienes produced by macrophages, neutrophils, and other inflammatory cells $[1,2]$. Activated macrophages play a particularly important role in the mediation of inflammation via the generation

\footnotetext{
* Correspondence: hkkim@kiom.re.kr

Herbal Medicine Resources Group, Korea Institute of Oriental Medicine, Yuseongdae-ro 1672, Yuseong-gu, Daejeon 305-811, Republic of Korea
}

of tumor necrosis factor- $\alpha$ (TNF- $\alpha$ ), interleukin-6 (IL-6), $\mathrm{NO}$, and prostaglandin $\mathrm{E}_{2}\left(\mathrm{PGE}_{2}\right)$. Of these, $\mathrm{NO}, \mathrm{PGE}_{2}$ are generated by inducible nitric oxide synthase (iNOS) and cyclooxygenase-2 (COX-2), respectively $[3,4]$.

Overproduction of these assorted inflammatory mediators is involved in the pathogenesis of atherosclerosis, inflammatory arthritis, and cancer [5]. Thus, identification of natural product-derived extracts that inhibit the production of inflammatory mediators is extremely attractive in terms of the development of functional foods for disease treatment and/or prevention [6]. 
Many previous studies have shown that various phytochemicals exert anti-inflammatory effects by inhibiting the nuclear factor $\kappa \mathrm{B}(\mathrm{NF}-\mathrm{\kappa} \mathrm{B})$ signaling pathway [7-11]. $\mathrm{NF}-\mathrm{kB}$ is a predominant transcription factor involved in the regulation of immune and inflammatory responses. The activation of NF- $\mathrm{kB}$ occurs via phosphorylation and degradation of $\mathrm{I} \kappa \mathrm{B}$ bound to $\mathrm{NF}-\kappa \mathrm{B}$, resulting in the translocation of NF- $\mathrm{kB}$ into the nucleus to promote the expression of pro-inflammatory mediators (i.e., iNOS, COX-2, and certain cytokines) [12]. Mitogen-activated protein kinase (MAPK) signaling pathways also modulate inflammatory responses through the upregulation of cytokine expression [13]. At the molecular level, the chemopreventive activities of anti-inflammatory substances are often attributed to their ability to target the components of pro-inflammatory signaling pathways, especially those mediated by a panel of upstream kinases and transcription factors [14]. Therefore, NF- $\mathrm{kB}$ and MAPKs are critical targets for the actions of anti-inflammatory molecules.

Houttuynia cordata Thunb. (family Saururaceae) is a perennial food plant widely distributed throughout Southeastern Asia. This plant is a leaf vegetable that is used as a herbal tea, in salads, or cooked with other vegetables [15]. Also, It has been used in traditional medicine for treatment of suppuration, chronic bronchitis and pneumonia, otitis, and cystitis [16,17]. H. cordata contains a number of polyphenolic components and is characterized by various pharmacological functions, including antioxidant, anti-inflammatory, anti-tumor, and anti-allergy properties [18-22]. Recent reports have demonstrated that the volatile oil and supercritical extract constituents of $H$. cordata are acutely important for the mitigation of inflammation [20,23,24]. Another recent study demonstrated that the ethyl acetate fraction of a $H$. cordata extract exerted a protective effect against chemokine (C-C motif) ligand 4 (CCL4)-induced acute hepatotoxicity in mice [15].

Despite these encouraging studies, the cellular and molecular mechanisms responsible for the anti-inflammatory activity of $H$. cordata have yet to be elucidated. Therefore, the present study compared the anti-inflammatory actions of $H$. cordata extract (HCE) and with those of various HCE fractions, by measuring their ability to inhibit NO, $\mathrm{PGE}_{2}$, TNF- $\alpha$, and IL- 6 production. Next, we investigated the molecular mechanisms underlying the antiinflammatory impact of the most efficacious fraction of $\mathrm{HCE}$, the HCE ethyl acetate fraction (HCE-EA).

\section{Methods}

\section{Chemicals and reagents}

Lipopolysaccharide (LPS), bovine serum albumin (BSA), and other common chemicals were purchased from Sigma-Aldrich Chemical Co. (St. Louis, MO, USA).
Primary and secondary antibodies for Western blotting analysis were purchased from Santa Cruz Biotechnology (Santa Cruz, CA, USA). ELISA kits were obtained from R\&D Systems (Minneapolis, MN, USA). The RNA extraction kit was obtained from Qiagen (Hilden, Germany). The Nuclear Extract Kit was purchased from Active Motif (Carlsbad, CA, USA). Standard compounds for ultra-high performance liquid chromatography (UPLC) analysis of $H$. cordata were as follows: chlorogenic acid (SigmaAldrich, Steinheim, Germany), hyperoside (Carl Roth $\mathrm{GmbH}$, Karlsruhe, Germany), and quercitrin (Wako Pure Chemical Industries Ltd, Osaka, Japan).

\section{Plant materials and sample preparation}

$H$. cordata was purchased from Omniherb Co. (Yeoungcheon, Korea) and authenticated based on the macroscopic characteristics described by the Classification and Identification Committee of the Korea Institute of Oriental Medicine (KIOM). The committee was composed of nine experts in the fields of plant taxonomy, botany, pharmacognosy, and herbology. A voucher specimen (KIOM008013) was deposited in the herbarium of the Department of Herbal Medicine Resource at KIOM. $H$. cordata $(3 \mathrm{~kg}$ ) was extracted three times with $70 \%$ ethanol (with a 2 h reflux), and the extract was concentrated under reduced pressure and lyophilized. The resulting extract $(663.1 \mathrm{~g})$ was resuspended in water and partitioned sequentially with $n$-hexane, methylene chloride, ethyl acetate, $n$-butanol, and water, followed by in vacuo evaporation to yield the $n$-hexane fraction (HCE-Hx, $70.9 \mathrm{~g}$ ), the methylene chloride fraction (HCE-MC, $17.9 \mathrm{~g}$ ), the ethyl acetate fraction (HCE-EA, $24.6 \mathrm{~g}$ ), the $n$-butanol fraction (HCE-BuOH, $96.6 \mathrm{~g}$ ), and the HCEwater fraction $(228.6 \mathrm{~g})$.

\section{Cell culture}

RAW 264.7 murine macrophages were obtained from the American Type Culture Collection (ATCC, Rockville, MD, USA) and maintained in Dulbecco's modified Eagle's medium (DMEM) supplemented with $5.5 \%$ fetal bovine serum (FBS) and $1 \%$ penicillin/streptomycin at $37^{\circ} \mathrm{C}$ in a humidified $5 \% \mathrm{CO}_{2}$ incubator.

\section{Cell viability}

Cell viability was measured by using the Cell Counting Kit8 (CCK-8) assay according to the manufacturer's instructions (Dojindo Molecular Technologies, Inc., Rockville, MD, USA). RAW 264.7 cells were seeded into a 96-well plate at a density of $5 \times 10^{4}$ cells/well. After $24 \mathrm{~h}$, the cells were treated with $\mathrm{HCE}(100 \mu \mathrm{g} / \mathrm{mL})$ plus LPS (1 $\mu \mathrm{g} / \mathrm{mL}$ ), the HCE-Hx, HCE-MC, HCE-BuOH, or HCE-water fraction $(100 \mu \mathrm{g} / \mathrm{mL})$ plus LPS $(1 \mu \mathrm{g} / \mathrm{mL})$, the HCE-EA fraction $(25,50,100$, or $200 \mu \mathrm{g} / \mathrm{mL})$ plus LPS $(1 \mu \mathrm{g} / \mathrm{mL})$, or LPS alone for an additional $24 \mathrm{~h}$. The 
Table 1 Sequences of primers used in real-time PCR

\begin{tabular}{lllll}
\hline Gene & \multicolumn{1}{c}{ Forward } & Reverse & Accession no. & Length (bp) \\
\hline iNOS & AAGGTCTACGTTCAGGACATC & AGAAATAGTCTTCCACCTGCT & NM_010927 \\
COX-2 & TTCCTCTACATAAGCCAGTGA & TCCACATTACATGCTCCTATC & NM_011198 \\
GAPDH & TGTGTCCGTCGTGGATCTGA & CCTGCTTCACCACCTTCTTGA & NM_008084 & 187 \\
\hline
\end{tabular}

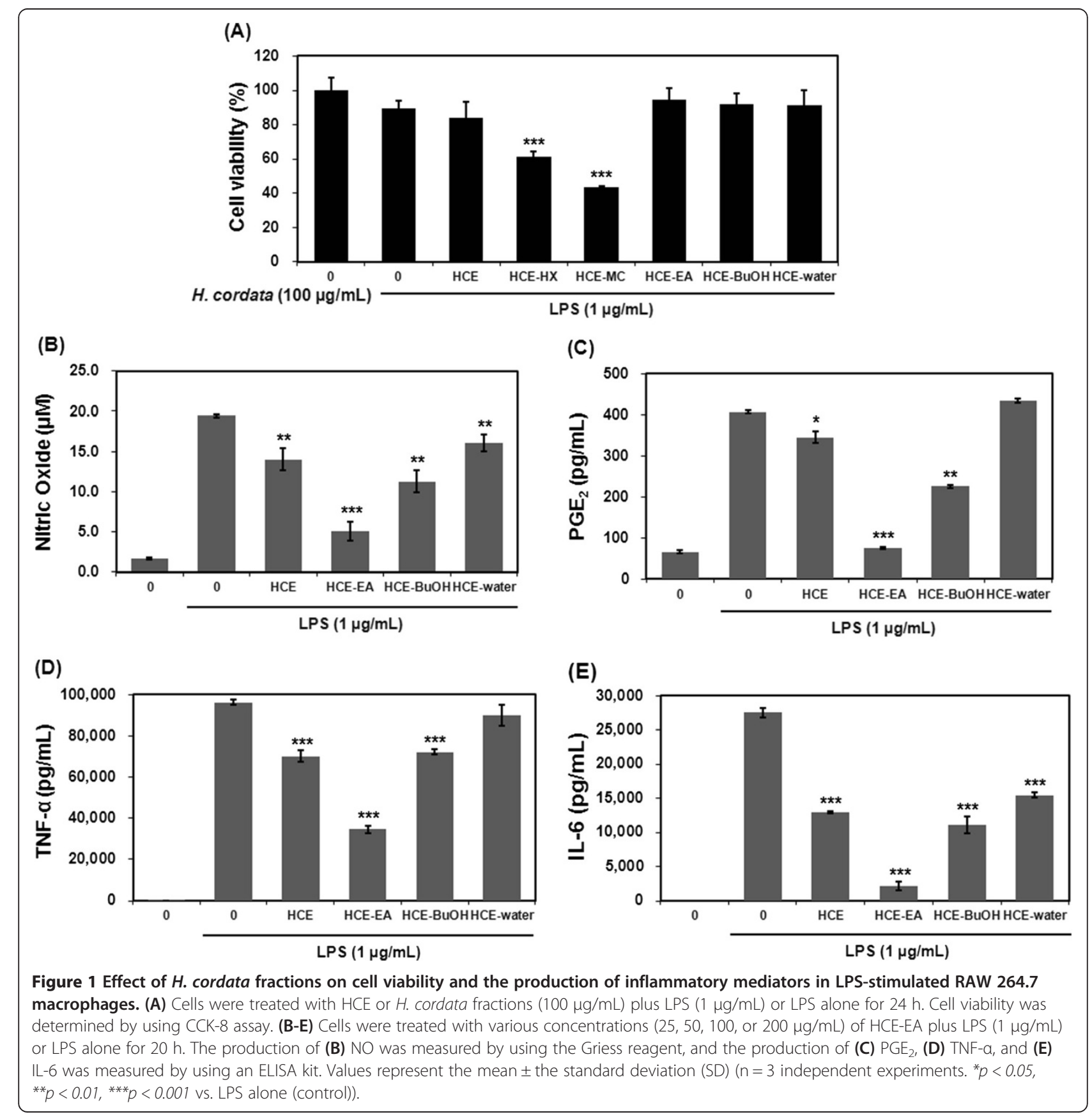



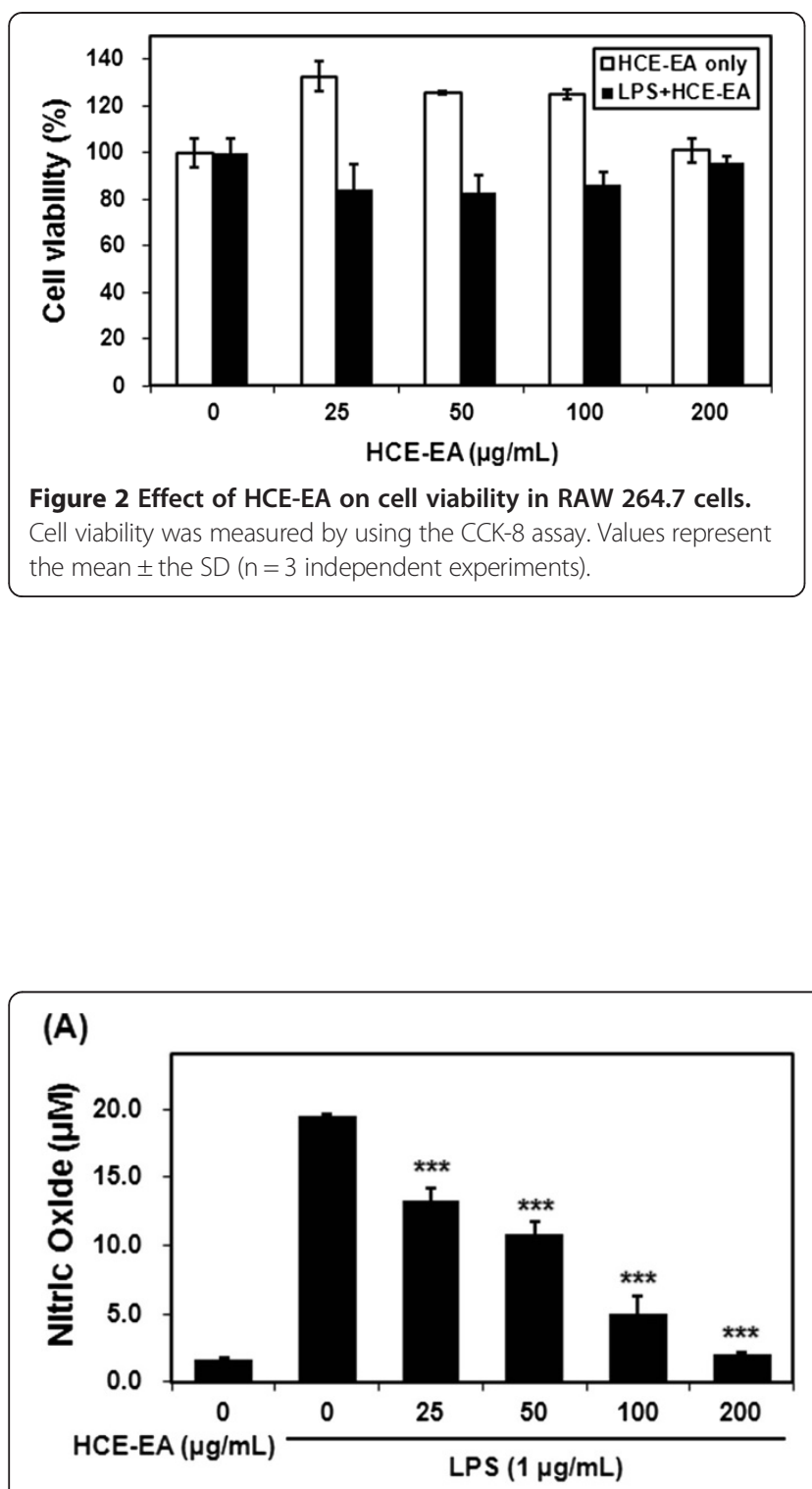

(C)

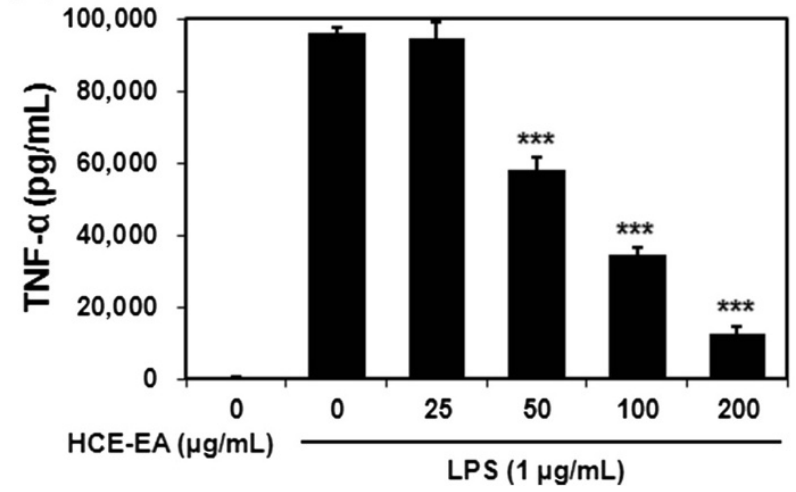

CCK- 8 assay was employed after another $1 \mathrm{~h}$ to assess cell viability, and the absorbance at $450 \mathrm{~nm}$ was mea-

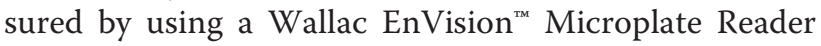
(PerkinElmer, MA, USA).

\section{Measurement of NO production}

The nitrite concentration in the culture medium was measured as an indicator of NO production by the Griess reaction system (Promega, WI, USA). RAW 264.7 cells $\left(5 \times 10^{4}\right.$ cells/well $)$ in 96-well plates were cultured for $24 \mathrm{~h}$. The cells were then treated with the samples list above plus LPS $(1 \mu \mathrm{g} / \mathrm{mL})$ or LPS alone for $20 \mathrm{~h}$. The supernatant was mixed with the same volume of Griess reagent and incubated at room temperature for $5 \mathrm{~min}$. The concentration of nitrite was determined by measuring the absorbance with a Wallac EnVision ${ }^{\text {tx }}$ Microplate Reader (PerkinElmer).

Determination of $\mathrm{PGE}_{2}$, TNF- $\alpha$, and IL- 6 production RAW 264.7 cells $\left(5 \times 10^{4}\right.$ cells/well in 96-well plates) were treated for $20 \mathrm{~h}$ with HCE plus LPS $(1 \mu \mathrm{g} / \mathrm{mL})$, the HCE-Hx, HCE-MC, HCE-BuOH, or HCE-water fraction $(100 \mu \mathrm{g} / \mathrm{mL})$ plus LPS $(1 \mu \mathrm{g} / \mathrm{mL})$, the HCE-EA fraction

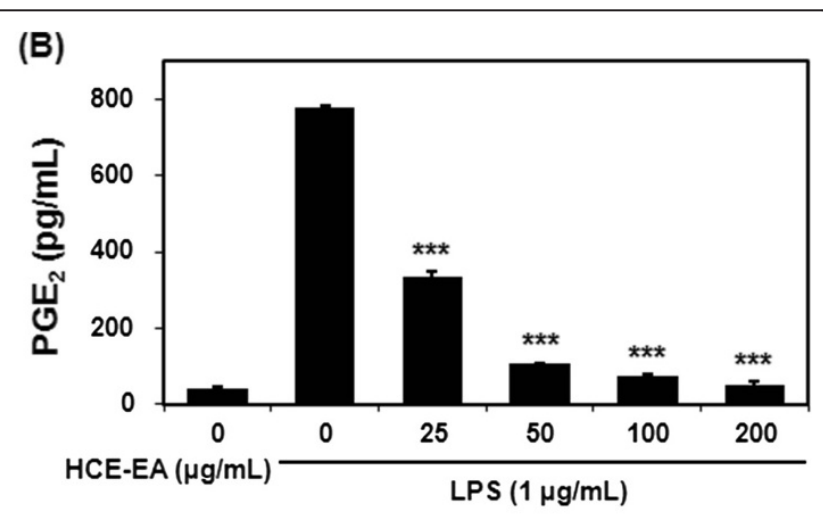

(D)

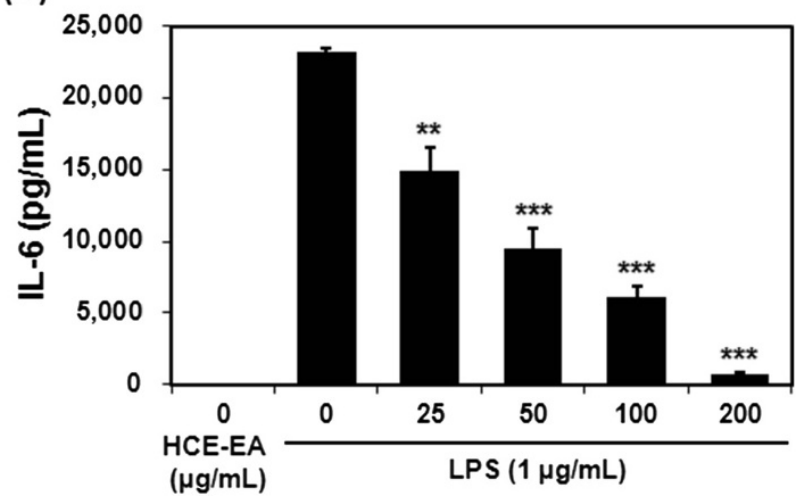

Figure 3 Effect of HCE-EA on the production of inflammatory mediators in LPS-stimulated RAW 264.7 macrophages. Cells were treated with various concentrations $(0,25,50,100$ or $200 \mu \mathrm{g} / \mathrm{mL})$ of HCE-EA plus LPS $(1 \mu \mathrm{g} / \mathrm{mL})$ or LPS alone for $20 \mathrm{~h}$. (A) NO content in the conditioned medium was measured by using the Griess reagent. (B-D) PGE 2 , TNF-a, and IL-6 production were determined by using an ELISA kit. Each bar represents the mean \pm the SD $\left(n=3\right.$ independent experiments ${ }^{* *} p<0.01,{ }^{* * *} p<0.001$ vs. LPS alone (control)). 
(25, 50, 100, $200 \mu \mathrm{g} / \mathrm{mL})$ plus LPS $(1 \mu \mathrm{g} / \mathrm{mL})$, or LPS alone. The conditioned medium was then collected. The production of $\mathrm{PGE}_{2}$, TNF- $\alpha$ and IL- 6 in the conditioned media was determined by using an ELISA kit (R\&D systems) according to the manufacturer's instructions.

\section{RNA extraction and quantitative real-time polymerase chain reaction (RT-PCR)}

RAW 264.7 cells $\left(5 \times 10^{5}\right.$ cells/well in six-well plates $)$ were treated with $\mathrm{HCE}-\mathrm{EA}(25,50,100$, or $200 \mu \mathrm{g} / \mathrm{mL})$ plus LPS $(1 \mu \mathrm{g} / \mathrm{mL})$ for $6 \mathrm{~h}$. To evaluate the expression levels of iNOS and COX-2 mRNA, total cellular RNA was extracted with an RNeasy mini kit (Qiagen) according to the manufacturer's instructions. Total RNA (500 ng) was mixed with Omniscript RT mixture (Qiagen) containing oligo-dT primers and water to a final volume of $20 \mu \mathrm{L}$ and incubated at $37^{\circ} \mathrm{C}$ for $60 \mathrm{~min}$. Real-time PCR was performed by using the Rotor Gene Q system (Qiagen, Hilden, Germany) and a reaction mixture that consisted of SYBR Green $2 \times$ PCR Master Mix, cDNA template, and forward and reverse primers. The PCR protocol consisted of 35 cycles of denaturation at $95^{\circ} \mathrm{C}$ for $15 \mathrm{sec}$, followed by $55^{\circ} \mathrm{C}$ for $30 \mathrm{sec}$ to allow for extension and amplification of the target sequence. The expression levels of iNOS and COX-2 mRNA were normalized to that of glyceraldehyde 3-phosphate dehydrogenase (GAPDH) via the $2-\Delta \Delta C T$ method. The primer sequences employed in this study are shown in Table 1.

\section{Preparation of cytosolic and nuclear extracts}

RAW 264.7 cells $\left(5 \times 10^{5}\right.$ cells/well in 6 -well plates) were pretreated with HCE-EA $(25,50,100$, or $200 \mu \mathrm{g} / \mathrm{mL})$ for $2 \mathrm{~h}$, followed by stimulation with LPS $(1 \mu \mathrm{g} / \mathrm{mL})$ for $1 \mathrm{~h}$. The preparation of nuclear and cytoplasmic extracts was performed by using the Nuclear Extract Kit (Active Motif). Lysates were collected and cleared by centrifugation, and the fractions were stored at $-80^{\circ} \mathrm{C}$ prior to use.

\section{Western blotting analysis}

RAW 264.7 cells $\left(5 \times 10^{5}\right.$ cells/well in 6 -well plates) were pretreated with HCE-EA $(25,50,100$, or $200 \mu \mathrm{g} / \mathrm{mL})$ for $2 \mathrm{~h}$, followed by stimulation with LPS $(1 \mu \mathrm{g} / \mathrm{mL})$. The

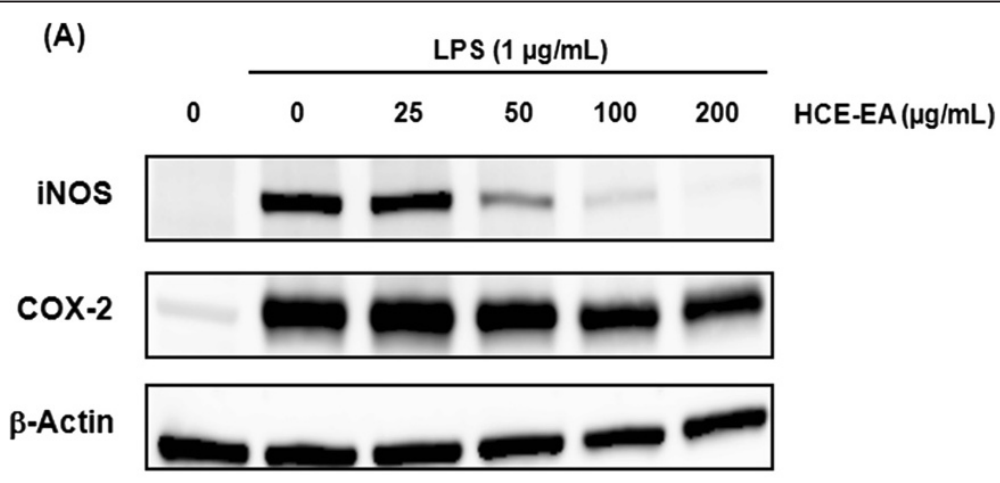

(B)

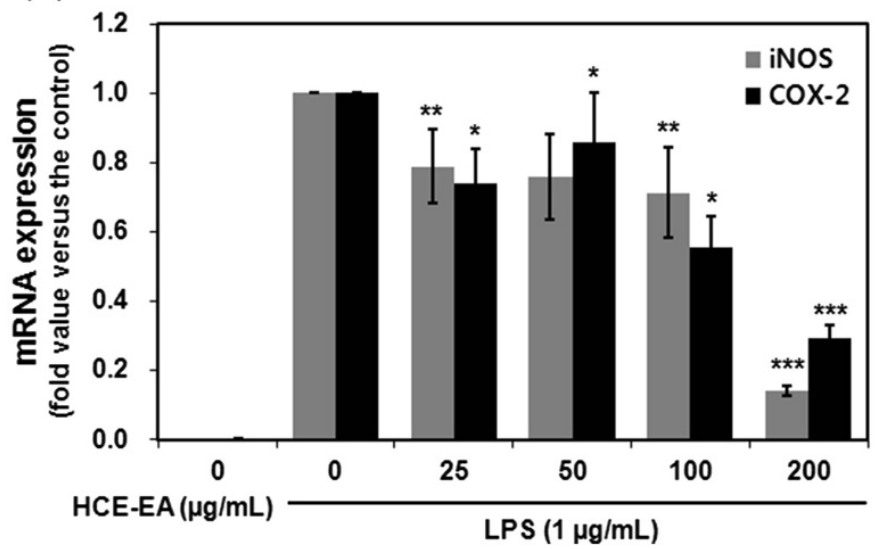

Figure 4 Effect of HCE-EA on iNOS and COX-2 protein and mRNA expression in LPS-stimulated RAW 264.7 macrophages. (A) Cells were treated with the indicated concentrations of HCE-EA plus LPS $(1 \mu \mathrm{g} / \mathrm{mL})$ or LPS alone for 20 h. Protein expression levels of iNOS and COX-2 were determined by Western blotting analysis. $\beta$-actin was employed as a loading control. (B) Cells were incubated with the indicated concentrations of HCE-EA LPS $(1 \mu \mathrm{g} / \mathrm{mL})$ or LPS alone for $6 \mathrm{~h}$. mRNA expression levels of iNOS and COX-2 were determined by real-time PCR analysis. The expression level of GAPDH mRNA served as the internal control for the normalization of iNOS and COX-2 mRNA expression. Data are expressed as the mean \pm the $\mathrm{SD}\left(\mathrm{n}=3\right.$ independent experiments ${ }^{*} p<0.05,{ }^{* *} p<0.01,{ }^{* *} p<0.001$ vs. LPS alone (control)). 
cells were collected and washed twice with cold phosphate buffered saline (PBS). Total cellular proteins were extracted with a protein lysis buffer (Pro-prep, iNtRON, Sungnam, Korea). Equal amounts of protein $(20 \mu \mathrm{g})$ were separated by sodium dodecyl sulfate-polyacrylamide gel electrophoresis (SDS-PAGE) in 12\% gels, followed by transfer onto nitrocellulose membranes. Membranes were blocked with $5 \%$ non-fat milk and incubated with primary antibodies overnight at $4^{\circ} \mathrm{C}$. The membranes were then incubated with the corresponding horseradish peroxidase-conjugated secondary antibodies for $1 \mathrm{~h}$ at room temperature. Membranes were treated with enhanced chemiluminescence detection reagents, and protein bands were visualized by using a Las-4000 Luminescent Image Analyzer (Fujifilm, Tokyo, Japan). Also, the densities of the bands were measured with the Multi Gauge software, version 3.0.

\section{Chromatographic conditions}

Chromatographic analysis was performed with a ultra performance liquid chromatography (UPLC) system (Waters Co., Milford, MA, USA) and a photodiode array detector. HCE and HCE-EA samples (10 mg) were dissolved in methanol $(10 \mathrm{~mL})$. Chromatographic separation was then conducted by using an Acquity UPLC HSS T3 column $(2.1 \times 100 \mathrm{~mm}, 1.8 \mu \mathrm{m}$, Waters Co). The mobile phase consisted of $0.2 \%$ acetic acid in water (A) and acetonitrile
(B), and the gradient program encompassed a linear change in 0-12 min from 88:12 (v/v) to 75:25 (v/v). The detection wavelength was scanned at $210-400 \mathrm{~nm}$ and recorded at $254 \mathrm{~nm}$. A flow rate of $0.2 \mathrm{~mL} / \mathrm{min}$ was applied, and the sample injection volume was $1.0 \mu \mathrm{L}$.

\section{Instrumentation and analytical conditions}

The liquid chromatography mass spectrometry (LC/MS) analysis was performed using an Waters UPLC system equipped with $15 \mathrm{~T}$ Fourier transform ion cyclotron resonance mass spectrometry (15 T FT-ICR MS) (Bruker, Billerica, MA) coupled with electrospray ionization (ESI). The mobile phase consisted of $0.1 \%$ formic acid in water (A) and $0.1 \%$ formic acid in acetonitrile (B) and the gradient program encompassed a linear change in 0-12 min from 88:12 (v/v) to 75:25 (v/v). Other LC/MS analysis condition was carried out in the same method with UPLC-PDA. Mass spectrometric acquisition was performed in scan mode using positive and mass range from $m / z 150$ to 2000 . The ion source dependent parameters were: source accumulation, $0.020 \mathrm{sec}$; ion accumulation time, $0.400 \mathrm{sec}$; ion spray voltage floating $4500 \mathrm{~V}$; dry Gas, $4.0 \mathrm{~L} / \mathrm{min}$; dry temperature, $180^{\circ} \mathrm{C}$; nebulizer, 2.0 bar.

\section{Statistical analysis}

All results are presented as the mean \pm the standard deviation (SD) and are representative of three or more

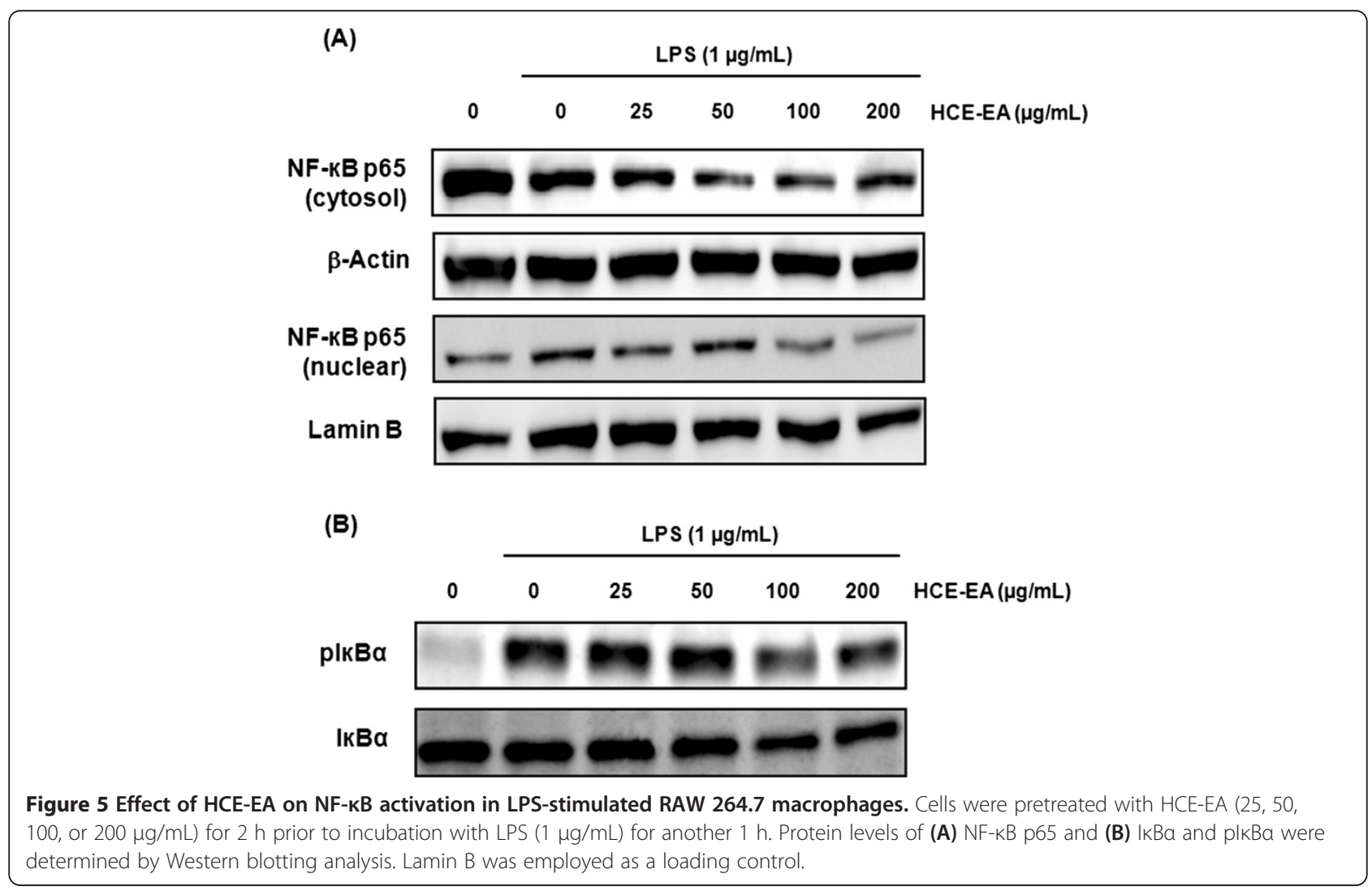


independent experiments. Data were compared by using Student's $t$-test and $P$-values less than 0.05 were considered statistically significant.

\section{Results}

Effect of HCE and its associated fractions on cell viability and LPS-induced production of NO, PGE 2 , TNF-a, and IL- 6 The CCK-8 assay was employed to determine the effect of HCE and the HCE-Hx, HCE-MC, HCE-EA, HCE-BuOH, and HCE-water fractions on RAW 264.7 cell viability. As shown in Figure 1A, The HCE-Hx and HCE-MC fractions exhibited marked cytotoxicity toward the cells. Therefore, HCE-Hx and HCE-MC were excluded from the remaining experiments. Next, we investigated the impact of HCE, HCE-EA, HCE-BuOH, and HCE-water on LPS-stimulated production of $\mathrm{NO}, \mathrm{PGE}_{2}, \mathrm{TNF}-\alpha$, and IL-6. Of these, HCE-EA was the most efficacious in regard to inhibition of the LPS-induced release of inflammatory mediators (Figure 1B-E). Thus, the HCE-EA fraction was selected for further study to assess the anti-inflammatory mechanism of $H$. cordata.

\section{Dose-dependent effect of HCE-EA on cell viability}

The influence of various concentrations of HCE-EA on RAW 264.7 cell viability was next investigated to establish the appropriate concentration range for the remainder of the study. HCE-EA did not affect cell viability at concentrations up to $200 \mu \mathrm{g} / \mathrm{mL}$ (Figure 2). Thus, we used HCE-EA at $25-200 \mu \mathrm{g} / \mathrm{mL}$ in subsequent experiments.

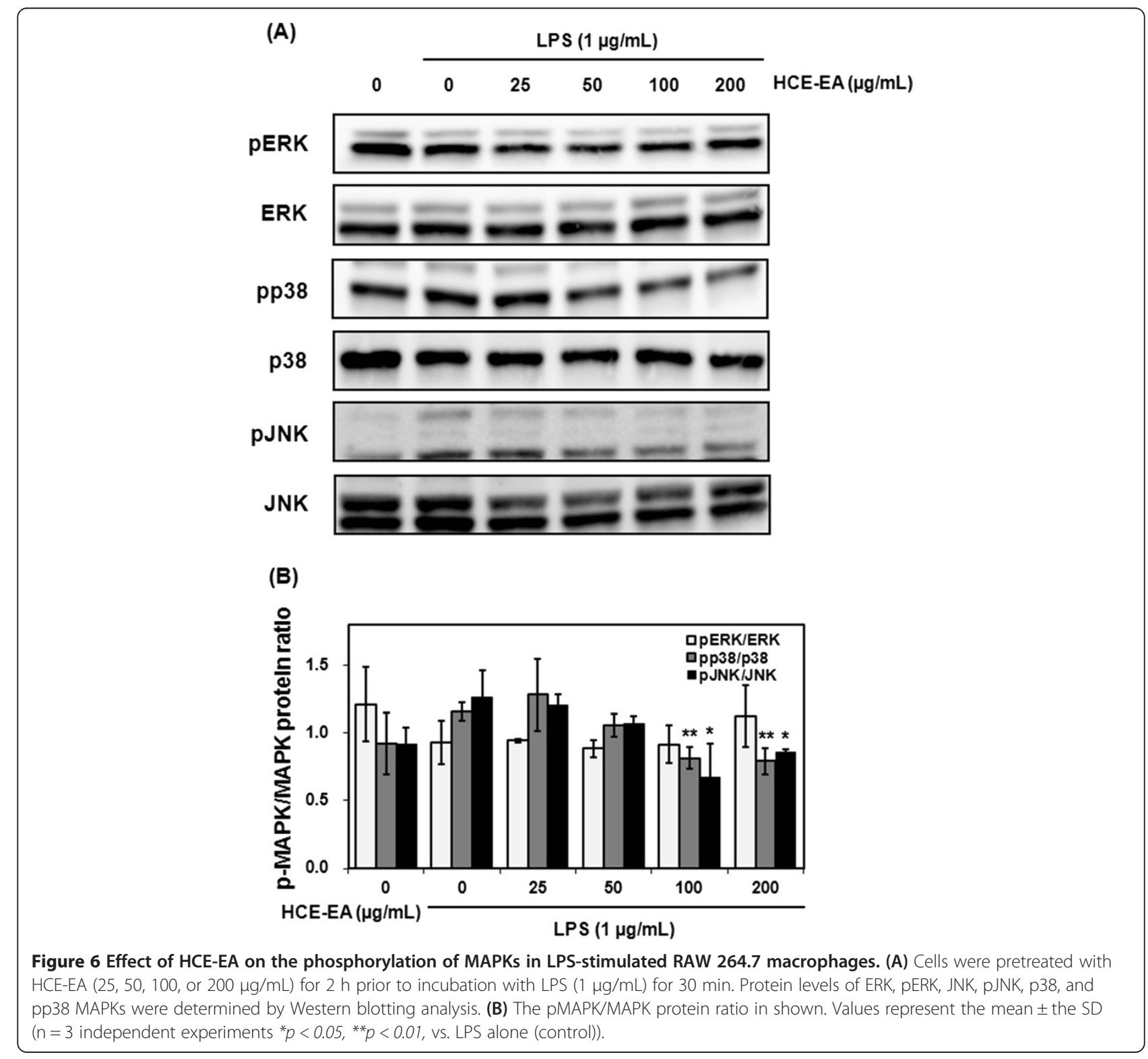


(A)

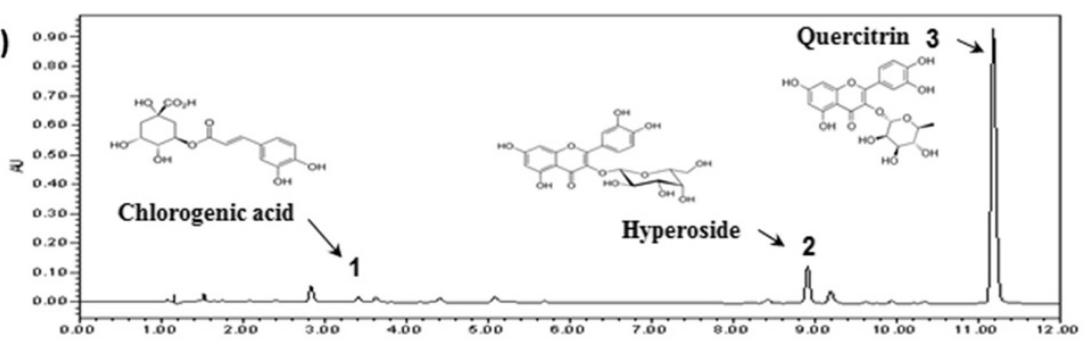

(B)

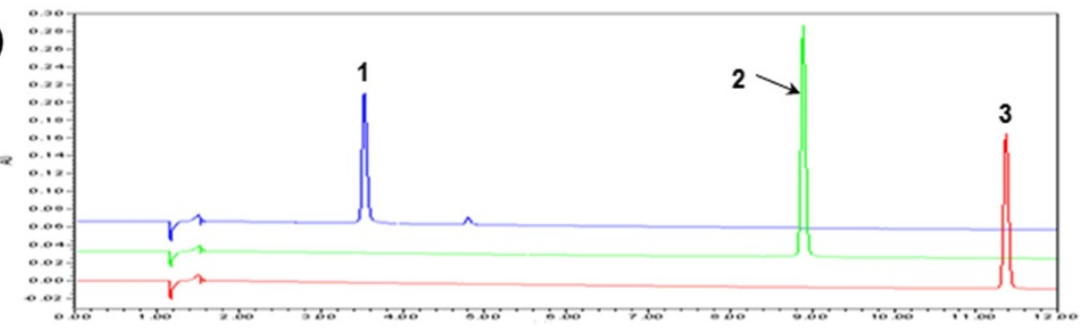

(C)

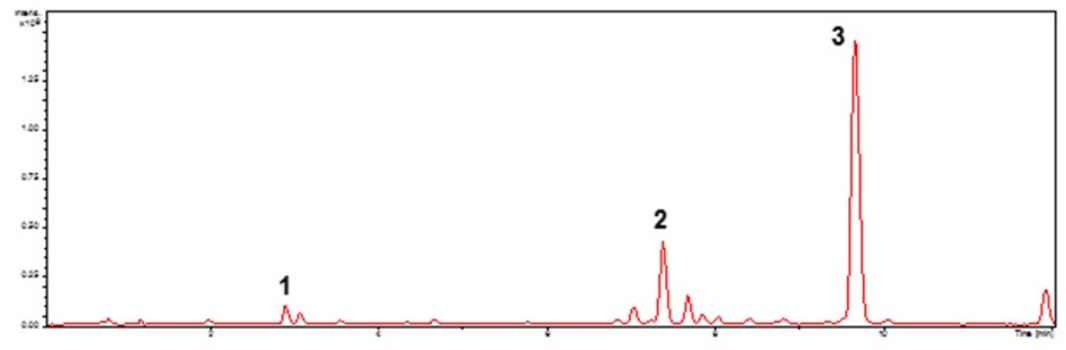

(D)

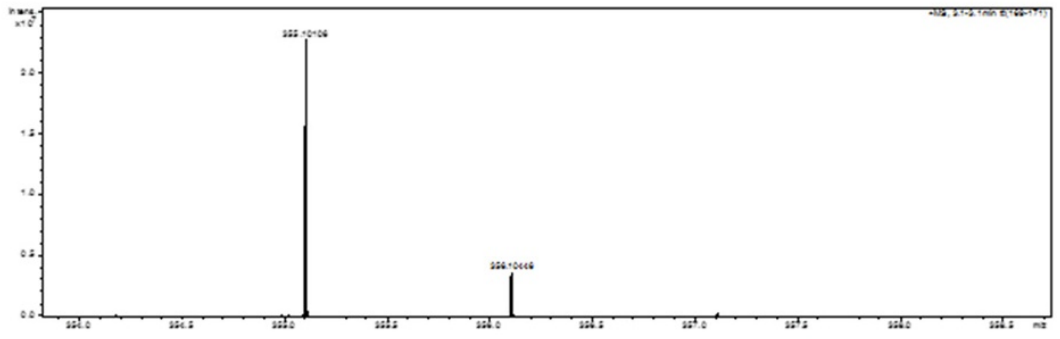

(E)

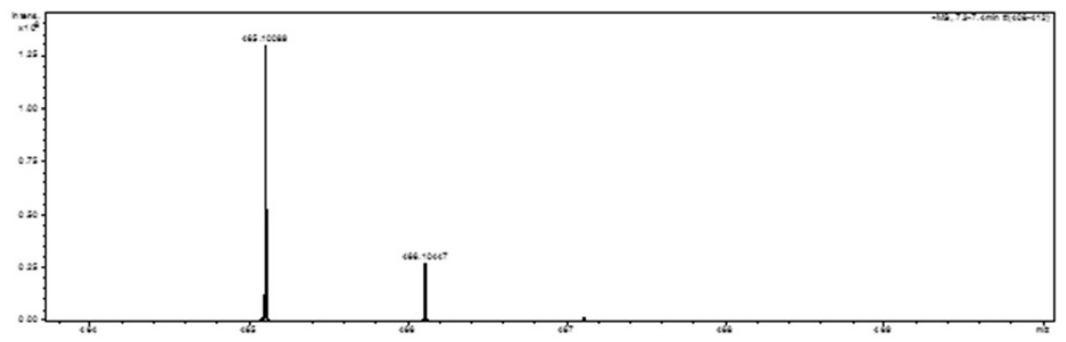

(F)

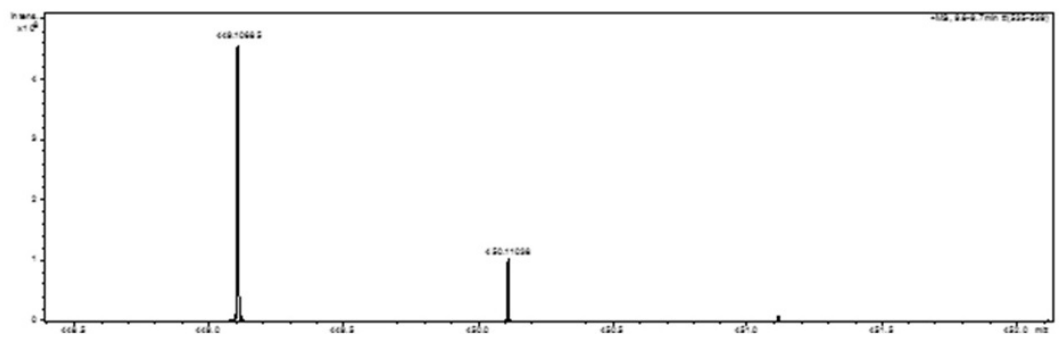

Figure 7 Representative UPLC chromatogram and mass spectra. (A) HCE-EA, (B) Peaks represent of standard compounds: (1) chlorogenic acid, (2) hyperoside, and (3) quercitrin, (C) total ion chromatogram of HCE-EA, (D) mass spectra of chlorogenic acid, (E) mass spectra of hyperoside, (F) mass spectra of quercitrin. 


\section{Effect of HCE-EA on LPS-stimulated production of NO, $\mathrm{PGE}_{2}, \mathrm{TNF}-\mathrm{a}$, and IL- 6}

To investigate whether HCE-EA inhibits LPS-stimulated production of NO, PGE 2 , TNF- $\alpha$, and IL-6, cells were treated with various concentrations of HCE-EA plus LPS or LPS alone for $20 \mathrm{~h}$. HCE-EA significantly decreased NO, PGE 2 , TNF- $\alpha$, and IL- 6 levels in a dose-dependent manner (Figure 3). The $\mathrm{IC}_{50}$ values of $\mathrm{NO}, \mathrm{PGE}_{2}$, TNF$\alpha$, and IL- 6 were estimated to be $58.64 \pm 5.25,22.12 \pm$ $2.78,70.99 \pm 5.84$, and $40.61 \pm 1.54 \mu \mathrm{g} / \mathrm{mL}$, respectively.

\section{Effects of HCE-EA on LPS-stimulated expression of iNOS and $\mathrm{COX}-2$}

Next, we investigated whether the inhibitory effect of $\mathrm{HCE}-\mathrm{EA}$ on $\mathrm{NO}$ and $\mathrm{PGE}_{2}$ production was related to the modulation of iNOS and COX-2 protein levels. Figure 4A demonstrates that HCE-EA strongly suppressed the protein expression of both iNOS and COX-2. Furthermore, HCE-EA also significantly repressed iNOS and COX-2 mRNA expression in LPS-stimulated RAW 264.7 cells (Figure 4B). These results suggest that the HCE-EAmediated inhibition of $\mathrm{NO}$ and $\mathrm{PGE}_{2}$ production is associated with transcriptional downregulation of iNOS and COX-2 genes.

\section{Effect of HCE-EA on LPS-induced NF-KB activation}

Activation of NF- $\mathrm{kB}$, an essential transcription factor in the inflammatory response, occurs following the phosphorylation, ubiquitination, and proteolytic degradation of IкB $\alpha$. Thus, p65 levels in cytoplasmic and nuclear extracts prepared from RAW 264.7 cells were next evaluated by Western blotting analysis. HCE-EA inhibited LPS-stimulated nuclear translocation of NF- $\mathrm{B}$ p 65 in a dose-dependent manner (Figure 5A). We also examined the ability of HCE-EA to inhibit the phosphorylation and degradation of IKB $\alpha$ in the cytoplasm and found that HCE-EA promoted the cytosolic accumulation of IкB $\alpha$ via suppression of $\mathrm{I} \kappa \mathrm{B} \alpha$ phosphorylation (Figure $5 \mathrm{~B}$ ). These results suggest HCE-EA effectively inhibits LPSinduced NF- $\mathrm{kB}$ activation by blocking the nuclear trans-

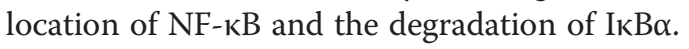

\section{Effect of HCE-EA on LPS-stimulated phosphorylation of MAPKs}

The phosphorylation and activation of MAPKs are crucial for LPS-stimulated NF- $\mathrm{KB}$ activation and the subsequent activation of inflammatory mediators [25]. To investigate whether HCE-EA attenuates inflammatory responses through MAPK pathways, we employed Western blotting to evaluate the phosphorylation levels of several MAPKs, including extracellular signal regulated kinase (ERK) $1 / 2$, c-Jun N-terminal kinase (JNK), and p38. HCE-EA suppressed the LPS-induced phosphorylation of JNK and p38, but not ERK 1/2 (Figure 6). This observation is consistent with the hypothesis that HCE-EA blocks JNK and p38 phosphorylation in MAPK pathways to suppress inflammatory responses in LPS-induced RAW 264.7 cells.

\section{Identification of the primary active components in HCE-EA}

UPLC-PDA and LC/MS analysis was next performed to identify the primary functional compounds in HCE-EA. The chromatogram and mass spectra of three components (chlorogenic acid, hyperoside, and quercitrin) are shown in Figure 7. The three components in HCE-EA were detected at approximately $3.4,8.9$ and $11.3 \mathrm{~min}$, respectively (Figure 7A and B). The molecular weight of three components was confirmed by LC/MS and their mass spectra. The product ion scan spectra of $[\mathrm{M}+\mathrm{H}]^{+}$ for chlorogenic acid, hyperoside, and quercitrin, showed molecular peak at $m / z 355.10,465.10$, and 449.10 , respectively (Figure 7C-F). As shown in Table 2, three components were increased in HCE-EA compared with $\mathrm{HCE}$ and are thus candidates for the anti-inflammatory actions of HCE-EA.

\section{Discussion}

Inflammatory processes are distinguished by the generation of large amounts of the pro-inflammatory mediators $\mathrm{NO}$ and $\mathrm{PGE}_{2}$, which are in turn generated by iNOS and COX-2 enzymes, respectively [26]. NO signaling requires iNOS upregulation, whereas abundant COX-2 expression promotes $\mathrm{PGE}_{2}$ production and the activation of the proinflammatory $\mathrm{PGE}_{2}$ signaling cascade in response to inflammatory stimuli [27]. Pro-inflammatory cytokines (e.g., TNF- $\alpha$ and IL-6) evoke elevated levels of iNOS and COX2, followed by a significant increase in $\mathrm{NO}$ and $\mathrm{PGE}_{2}$ production. Therefore, the present study evaluated the anti-inflammatory actions of HCE-EA on LPS-stimulated RAW 264.7 cells and the molecular mechanisms involved in terms of TNF- $\alpha$, IL- 6 , iNOS, COX-2, NO, and PGE 2 production.

The current results showed that HCE-EA was more efficacious than the other fractions at suppressing the LPS-induced release of $\mathrm{NO}$ and $\mathrm{PGE}_{2}$, with no cytotoxicity at the concentrations employed. Moreover, HCEEA suppressed the LPS-stimulated increase in iNOS and COX-2 protein and mRNA expression. We also confirmed that HCE-EA decreased the levels of pro-inflammatory cytokines produced by LPS-treated RAW 264.7 cells (i.e., TNF- $\alpha$ and IL-6), and showed that the actions of HCE-EA

Table 2 Content of three compounds in HCE and HCE-EA

\begin{tabular}{lccc}
\hline Material & \multicolumn{3}{c}{ Content $(\mathbf{m g} / \mathbf{g})$} \\
\cline { 2 - 4 } & Chlorogenic acid & Hyperoside & Quercitrin \\
\hline HCE & $1.052 \pm 0.00$ & $4.342 \pm 0.02$ & $8.999 \pm 0.03$ \\
HCE-EA & $12.503 \pm 0.02$ & $38.705 \pm 0.07$ & $142.671 \pm 0.24$ \\
\hline
\end{tabular}


were mediated via inhibition of the NF-kB and MAPK signaling pathways. These pathways are well-known to modulate levels of pro-inflammatory mediators.

$\mathrm{NF}-\mathrm{kB}$ regulates the transcription of a number of genes, including iNOS, COX-2, TNF- $\alpha$, and IL-6, and is thus important for the development of inflammatory diseases $[7,12,14]$. Once activated, the NF-kB p65 subunit dissociates from its inhibitory protein IKB $\alpha$ and translocates from the cytoplasm into the nucleus [28]. We demonstrated herein that HCE-EA inhibits NF- $\mathrm{kB}$ activation via the blockade of LPS-induced ІкB $\alpha$ degradation and the subsequent nuclear translocation of the NF- $\mathrm{KB}$ p65 subunit. MAPK signaling pathways are also directly involved in the synthesis of pro-inflammatory cytokines in activated macrophages through the induction of NF- $\mathrm{KB}$ $[29,30]$. Therefore, NF-kB- and MAPKs- targeted therapeutics might be effective for the treatment of inflammatory diseases, given that a wide variety of pharmacologic agents reportedly inhibit activation steps in the NF- $\mathrm{kB}$ and MAPKs signaling pathways [13,31,32]. Consistent with these reports, the current study demonstrated that HCE-EA dose-dependently inhibited the phosphorylation of p38 and JNK MAPKs. These results suggest that the HCE-EA-mediated inhibition of NF- $\mathrm{kB}$ and MAPK activations is related to the reduced production of pro-inflammatory mediators in LPS-stimulated RAW 264.7 cells.

This study showed that the levels of three compounds (chlorogenic acid, hyperoside, and quercitrin) were elevated in HCE-EA compared with HCE. A previous study reported that chlorogenic acid exerted as antiinflammatory actions by inhibiting the LPS-provoked release of inflammatory cytokines in RAW 264.7 cells [33]. Additional studies demonstrated that hyperoside inhibited NO production in rat peritoneal macrophages and attenuated LPS-induced inflammatory responses through NF- $\kappa \mathrm{B}$ activation and I $\mathrm{KB}-\alpha$ degradation $[34,35]$. Yet another study revealed that quercitrin markedly overturned NO production in RAW 264.7 cells and inhibited the progression of inflammation through down-regulation of the NF-kB pathway [36,37]. Furthermore, Tian et al [15] reported that an EA fraction derived from $H$. cordata was rich in the polyphenolic compounds quercitrin, quercetin, and hyperoside, which were responsible for the antioxidant and hepatoprotective merits of the tea. In agreement with these previous studies, our results indicate that the ability of HCE-EA to suppress production of inflammatory mediators might be attributable to its content of active components, in particular chlorogenic acid, hyperoside, and quercitrin.

\section{Conclusions}

In conclusion, HCE-EA inhibited the production of NO, $\mathrm{PGE}_{2}$, iNOS, COX-2, TNF- $\alpha$, and IL-6 in LPS-treated
RAW 264.7 cells. The inhibitory effects were mediated by inhibition of NF-kB activation and MAPK (p38 and JNK) signaling pathways. Thus, HCE-EA may find utility as an attractive agent to prevent or reverse inflammatory responses.

\section{Competing interests}

The authors declare that they have no competing interest.

\section{Authors' contributions}

JMC, KJN and HKK participated in the design of the study data analyses and manuscript preparation. HSK, AYL, BCM carried out the Houttuynia cordata fractionation and analyzed the HPLC data. All authors read and approved the final manuscript.

\section{Acknowledgements}

This work was supported by the Construction of the Basis for Practical Application of Herbal Resources (K12020) and Efficacy study of Alternative Herbal Medicine Resources (K14416) from the Korea Institute of Oriental Medicine (KIOM) to the Ministry of Science, ICT \&Future Planning (MSIP), Korea.

Received: 16 August 2013 Accepted: 30 June 2014 Published: 10 July 2014

\section{References}

1. Kanterman J, Sade-Feldman M, Baniyash M: New insights into chronic inflammation-induced immunosuppression. Semin Cancer Biol 2012, 22(4):307-318.

2. Lawrence $T$ : The nuclear factor NF-kappaB pathway in inflammation. Cold Spring Harb Perspect Biol 2009, 1(6):a001651.

3. Liu G, Yang $\mathrm{H}$ : Modulation of macrophage activation and programming in immunity. J Cell Physiol 2013, 228(3):502-512.

4. Guastadisegni C, Nicolini A, Balduzzi M, Ajmone-Cat MA, Minghetti L: Modulation of PGE(2) and TNFalpha by nitric oxide and LPS-activated RAW 264.7 cells. Cytokine 2002, 19(4):175-180.

5. Libby P: Inflammatory mechanisms: the molecular basis of inflammation and disease. Nutr Rev 2007, 65(12 pt 2):S140-S146.

6. Prasad S, Phromnoi K, Yadav VR, Chaturvedi MM, Aggarwal BB: Targeting inflammatory pathways by flavonoids for prevention and treatment of cancer. Planta Med 2010, 76(11):1044-1063.

7. Lawrence T, Fong C: The resolution of inflammation: anti-inflammatory roles for NF-kappaB. Int J Biochem Cell Biol 2010, 42(4):519-523.

8. Yoon T, Cheon MS, Lee AY, do Lee Y, Moon BC, Chun JM, Choo BK, Kim HK: Anti-inflammatory activity of methylene chloride fraction from Glehnia littoralis extract via suppression of NF-kappa B and mitogen-activated protein kinase activity. J Pharmacol Sci 2010, 112(1):46-55.

9. Oh YC, Cho WK, Im GY, Jeong YH, Hwang YH, Liang C, Ma JY: Antiinflammatory effect of Lycium Fruit water extract in lipopolysaccharidestimulated RAW 264.7 macrophage cells. Int Immunopharmacol 2012, 13(2):181-189.

10. Kang CH, Choi YH, Park SY, Kim GY: Anti-inflammatory effects of methanol extract of Codium fragile in lipopolysaccharide-stimulated RAW 264.7 cells. J Med Food 2012, 15(1):44-50.

11. Lee MS, Kwon MS, Choi JW, Shin T, No HK, Choi JS, Byun DS, Kim Jl, Kim HR: Anti-inflammatory activities of an ethanol extract of Ecklonia stolonifera in lipopolysaccharide-stimulated RAW 264.7 murine macrophage cells. J Agric Food Chem 2012, 60(36):9120-9129.

12. Barnes PJ, Karin M: Nuclear factor-kappaB: a pivotal transcription factor in chronic inflammatory diseases. N Engl J Med 1997, 336(15):1066-1071.

13. Lee HS, Ryu DS, Lee GS, Lee DS: Anti-inflammatory effects of dichloromethane fraction from Orostachys japonicus in RAW 264.7 cells: suppression of NF-KB activation and MAPK signaling. J Ethnopharmacol 2012, 140(2):271-276.

14. Kundu JK, Surh YJ: Breaking the relay in deregulated cellular signal transduction as a rationale for chemoprevention with anti-inflammatory phytochemicals. Mutat Res 2005, 591(1-2):123-146.

15. Tian L, Shi X, Yu L, Zhu J, Ma R, Yang X: Chemical composition and hepatoprotective effects of polyphenol-rich extract from Houttuynia cordata tea. J Agric Food Chem 2012, 60(18):4641-4648. 
16. Huang KC: In the Pharmacology of Chinese Herbs. 2nd edition. Boca Raton, FL, USA: CRC Press; 1993:296.

17. World Health Organization Regional Office for the Western Pacific: Medicinal Plants in the Republic of Korea. Manila: WHO Regional Publications; 1998:145.

18. Han EH, Park JH, Kim JY, Jeong HG: Houttuynia cordata water extract suppresses anaphylactic reaction and IgE-mediated allergic response by inhibiting multiple steps of FcepsilonRI signaling in mast cells. Food Chem Toxicol 2009, 47(7):1659-1666.

19. Kusirisin W, Srichairatanakool S, Lerttrakarnnon P, Lailerd N, Suttajit M, Jaikang C, Chaiyasut C: Antioxidative activity, polyphenolic content and anti-glycation effect of some Thai medicinal plants traditionally used in diabetic patients. Med Chem 2009, 5(2):139-147.

20. Li W, Zhou P, Zhang Y, He L: Houttuynia cordata, a novel and selective COX-2 inhibitor with anti-inflammatory activity. J Ethnopharmacol 2011, 133(2):922-927.

21. Tang YJ, Yang JS, Lin CF, Shyu WC, Tsuzuki M, Lu CC, Chen YF, Lai KC: Houttuynia cordata Thunb extract induces apoptosis through mitochondrial-dependent pathway in HT-29 human colon adenocarcinoma cells. Oncol Rep 2009, 22(5):1051-1056.

22. Lai KC, Chiu YJ, Tang YJ, Lin KL, Chiang JH, Jiang YL, Jen HF, Kuo YH, Agamaya S, Chung JG, Yang JS: Houttuynia cordata Thunb extract inhibits cell growth and induces apoptosis in human primary colorectal cancer cells. Anticancer Res 2010, 30(9):3549-3556.

23. Shin S, Joo SS, Jeon JH, Park D, Jang MJ, Kim TO, Kim HK, Hwang BY, Kim KY, Kim YB: Anti-inflammatory effects of a Houttuynia cordata supercritical extract. J Vet Sci 2010, 11(3):273-275.

24. Kim D, Park D, Kyung J, Yang YH, Choi EK, Lee YB, Kim HK, Hwang BY, Kim YB: Anti-inflammatory effects of Houttuynia cordata supercritical extract in carrageenan-air pouch inflammation model. Lab Anim Res 2012, 28(2):137-140

25. Kaminska B: MAPK signalling pathways as molecular targets for anti-inflammatory therapy-from molecular mechanisms to therapeutic benefits. Biochim Biophys Acta 2005, 1754(1-2):253-262.

26. Lee SH, Soyoola E, Chanmugam P, Hart S, Sun W, Zhong H, Liou S, Simmons D, Hwang D: Selective expression of mitogen-inducible cyclooxygenase in macrophages stimulated with lipopolysaccharide. J Biol Chem 1992, 267(36):25934-25938.

27. Kundu JK, Surh YJ: Inflammation: gearing the journey to cancer. Mutat Res 2008, 659(1-2):15-30.

28. Surh YJ: Cancer chemoprevention with dietary phytochemicals. Nat Rev Cancer 2003, 3(10):768-780.

29. Guan Z, Buckman SY, Miller BW, Springer LD, Morrison AR: Interleukin1 beta-induced cyclooxygenase-2 expression requires activation of both c-Jun NH2-terminal kinase and p38 MAPK signal pathways in rat renal mesangial cells. J Biol Chem 1998, 273(44):28670-28676.

30. Li Q, Verma IM: NF-kappaB regulation in the immune system. Nat Rev Immunol 2002, 2(12):725-734

31. Himaya SW, Ryu B, Qian ZJ, Kim SK: Paeonol from Hippocampus kuda Bleeler suppressed the neuro-inflammatory responses in vitro via NF-KB and MAPK signaling pathways. Toxicol In Vitro 2012, 26(6):878-887.

32. Park HH, Kim MJ, Li Y, Park YN, Lee J, Lee YJ, Kim SG, Park HJ, Son JK, Chang HW, Lee E: Britanin suppresses LPS-induced nitric oxide, PGE2 and cytokine production via NF-KB and MAPK inactivation in RAW 264.7 cells. Int Immunopharmacol 2013, 15(2):296-302.

33. Shan J, Fu J, Zhao Z, Kong X, Huang H, Luo L, Yin Z: Chlorogenic acid inhibits lipopolysaccharide-induced cyclooxygenase-2 expression in RAW264.7 cells through suppressing NF-kappaB and JNK/AP-1 activation. Int Immunopharmacol 2009, 9(9):1042-1048.

34. Lee S, Park HS, Notsu Y, Ban HS, Kim YP, Ishihara K, Hirasawa N, Jung SH, Lee YS, Lim SS, Park EH, Shin KH, Seyama T, Hong J, Ohuchi K: Effects of hyperin, isoquercitrin and quercetin on lipopolysaccharide-induced nitrite production in rat peritoneal macrophages. Phytother Res 2008 22(11):1552-1556.

35. Kim SJ, Um JY, Lee JY: Anti-inflammatory activity of hyperoside through the suppression of nuclear factor-kB activation in mouse peritoneal macrophages. Am J Chin Med 2011, 39(1):171-181.
36. Mao YW, Tseng HW, Liang WL, Chen IS, Chen ST, Lee MH: Antiinflammatory and free radial scavenging activities of the constituents isolated from Machilus zuihoensis. Molecules 2011, 16(11):9451-9466.

37. Comalada M, Camuesco D, Sierra S, Ballester I, Xaus J, Gálvez J, Zarzuelo A: In vivo quercitrin anti-inflammatory effect involves release of quercetin, which inhibits inflammation through down-regulation of the NF-kappaB pathway. Eur J Immunol 2005, 35(2):584-592.

doi:10.1186/1472-6882-14-234

Cite this article as: Chun et al.: An ethyl acetate fraction derived from Houttuynia cordata extract inhibits the production of inflammatory markers by suppressing NF-KB and MAPK activation in lipopolysaccharidestimulated RAW 264.7 macrophages. BMC Complementary and Alternative Medicine 2014 14:234.

\section{Submit your next manuscript to BioMed Central and take full advantage of:}

- Convenient online submission

- Thorough peer review

- No space constraints or color figure charges

- Immediate publication on acceptance

- Inclusion in PubMed, CAS, Scopus and Google Scholar

- Research which is freely available for redistribution

Submit your manuscript at www.biomedcentral.com/submit
() Biomed Central 